\title{
Outpatient vs. home-based pulmonary rehabilitation in COPD: a randomized controlled trial
} Riabilitazione respiratoria ambulatoriale vs. domiciliare nella BPCO: studio randomizzato controllato

Júlio C. Mendes de Oliveira ${ }^{1,2}$, Fernando S. Studart Leitão Filho², Luciana M. Malosa Sampaio², Ana C. Negrinho de Oliveira ${ }^{1}$, Raquel Pastrello Hirata ${ }^{2}$, Dirceu Costa ${ }^{2}$, Claudio F. Donner ${ }^{3}$, Luís V.F. de Oliveira²

${ }^{1}$ Institute of the Lung, Cascavel, PR, Brazil

${ }^{2}$ Rehabilitation Sciences Master's Program Department, Nove de Julho University, Sao Paulo, SP, Brazil ${ }_{3}^{3}$ Mondo Medico, Multidisciplinary and Rehabilitation Outpatient Clinic, Borgomanero (NO), Italy

\section{ABSTRACT}

Background: Chronic obstructive pulmonary disease (COPD) is a common cause of morbidity and mortality affecting a large number of individuals in both developed and developing countries and it represents a significant financial burden for patients, families and society. Pulmonary rehabilitation (PR) is a multidisciplinary program that integrates components of exercise training, education, nutritional support, psychological support and self-care, resulting in an improvement in dyspnea, fatigue and quality of life. Despite its proven effectiveness and the strong scientific recommendations for its routine use in the care of COPD, PR is generally underutilized and strategies for increasing access to PR are needed. Homebased self-monitored pulmonary rehabilitation is an alternative to outpatient rehabilitation. In the present study, patients with mild, moderate and severe COPD submitted to either an outpatient or at-home PR program for 12 weeks were analyzed.

Methods: Patients who fulfilled the inclusion criteria were randomized into three distinct groups: an outpatient group who performed all activities at the clinic, a home-based group who performed the activities at home and a control group. PR consisted of a combination of aerobic exercises and strengthening of upper and lower limbs 3 times a week for 12 weeks.
Results: There was a significant difference in the distance covered on the six-minute walk test $(p<0.05)$ and BODE index ( $p$ $<0.001$ ) in the outpatient and at-home groups after participating in the rehabilitation program compared to baseline. Conclusion: A home-based self-monitoring pulmonary rehabilitation program is as effective as outpatient pulmonary rehabilitation and is a valid alternative for the management of patients with COPD.

Keywords: COPD, home-based pulmonary rehabilitation, pulmonary rehabilitation.

\section{RIASSUNTO}

Razionale: La broncopneumopatia cronica ostruttiva (BPCO) è una causa frequente di morbilità e mortalità che colpisce un'ampia quota di popolazione sia nel mondo industrializzato che nei Paesi in via di sviluppo e rappresenta un peso economico di rilievo per pazienti, familiari e collettività. La riabilitazione respiratoria (PR) è un programma multidisciplinare che inegra componenti di riallenamento all'esercizio fisico, educazionale, supporto nutrizionale, supporto psicologico ed autoaiuto, che porta ad un miglioramento della dispnea, della affaticabilità e della qualità della vita. Nonostante la provata efficacia e le forti raccomandazioni delle società scientifiche

” Luís V.F. de Oliveira

Rehabilitation Sciences Master's Program Department, Nove de Julho University

Rua Itapicuru, 380 - AP 111, Perdizes; 05006-000 São Paulo, SP, Brazil

email: oliveira.lvf@uninove.br

Nota: Study based on Julio Cesar Mendes de Oliveira's master's degree dissertation presented in 2009 to the Postgraduate Program in Rehabilitation Sciences of the Nove de Julho University (Brazil).

Data di arrivo del testo: 17/10/2010 - Accettato dopo revisione: 29/11/2010

Multidisciplinary Respiratory Medicine 2010; 5(6): 401-408 
al suo impiego routinario nel trattamento della BPCO, la PR è generalmente sottoutilizzata e si rendono perciò necessarie strategie per aumentarne l'utilizzo. La PR effettuata a domicilio ed auto-monitorata dal paziente stesso è un'alternativa alla classica riabilitazione ambulatoriale. In questo studio sono stati valuati pazienti con BPCO di grado lieve, moderato e grave sottoposti a un programma di PR ambulatoriale o domiciliare.

Metodi: I pazienti eligibili allo studio sono stati randomizzati in tre gruppi: un gruppo ambulatoriale che effettuava tutte le attività in ospedale, un gruppo domiciliare che effettuava il programma a domicilio ed un gruppo di controllo. Il programma di PR consisteva in una combinazione di esercizi aerobici e di rafforzamento della muscolatura degli arti superiori e inferiori per 3 volte la settimana per 12 settimane.

Risultati: Sia nel gruppo che ha partecipato al PR ambulatoriale che in quello domiciliare si sono rilevate differenze significative rispetto alle misure di base nella distanza coperta con il test del cammino di 6 minuti $(p<0.05)$ che nell'indice BODE ( $p<0.001)$.

Conclusioni: Un programma di riabilitazione respiratoria automonitorato eseguito a domicilio ha efficacia sovrapponibile ad un programma ambulatoriale e può perciò essere considerato una valida alternativa nella gestione del paziente con BPCO.

Parole chiave: BPCO, riabilitazione respiratoria domiciliare, riabilitazione respiratoria.

\section{INTRODUCTION}

Chronic obstructive pulmonary disease (COPD) is a common cause of illness and death that affects a large and increasing number of individuals in both developed and developing countries. Estimates suggest that COPD will become the $3^{\text {rd }}$ most common cause of death in the world and $5^{\text {th }}$ most common cause of illness in the next 20 years $[1,2]$.

Pulmonary rehabilitation (PR) is a multidisciplinary intervention that integrates physical exercise, nutritional therapy, patient education and psychological support [3-7]. Evidence indicates that PR offers numerous clinical benefits, such as improved health-related quality of life, a reduction in anxiety and depression, increased tolerance to physical exercise and a reduction in the number of hospitalizations and days of hospital stay per year $[3,4]$. However, despite the strong scientific recommendations for its routine use in the treatment of COPD, PR is generally underutilized [5-7]. A survey carried out in 2005 in Canada demonstrated that only 1-2\% of the Canadian population with COPD has access to rehabilitation programs [8]. Similar statistics are reported for other countries $[7,9]$.

A search of the scientific literature revealed few controlled studies that demonstrate the benefits of self-monitored pulmonary rehabilitation programs for patients with COPD. The majority of these studies demonstrate the effectiveness of home-based $\mathrm{PR}$, with similar results to those obtained in a clinical setting involving the direct supervision of physiotherapists [8-11]. The aim of the present study was to carry out a comparative analysis of patients with COPD submitted to PR in a clinical setting and at home.

\section{METHODS}

\section{Study design}

A randomized controlled prospective study with a consecutive sample was carried out. The study received approval from the Ethics Committee of the Nove de Julho University (Brazil) under protocol number 306654/2008. All participants gave their informed consent agreeing to participate in the study and were permitted to abandon the study at any time with no negative consequences.

The initial sample was made up of 216 patients who sought treatment at a private pulmonology clinic in the city of Cascavel (southern Brazil). The patients were randomized electronically by a computer into three groups as follows: outpatient rehabilitation, athome rehabilitation and a control group. The primary outcome was the difference in distance walked on the six-minute walk test (6MWT). The secondary outcome was the variation in the BODE index.

\section{Patients}

The following were the inclusion criteria: COPD based on the GOLD classification [1]; clinical stability in the eight weeks prior to the study (no reports of worsening of dyspnea, increased phlegm production or phlegm purulence). The exclusion criteria were: hospitalization; COPD instability; presence of neuromuscular disease, associated respiratory disease, orthopedic or neurological disease that affected gait; recent impairment due to comorbidities, such as myocardial infarction, heart failure, stroke or neoplasm; prior pneumonectomy or other thoracic surgery. The presence of stable comorbidities was not considered an exclusion criterion as most patients with COPD are elderly and commonly affected by multiple comorbidities [12]. All patients who sought care at the clinic and fulfilled these criteria were considered eligible for the study.

\section{Measurements}

All patients underwent a physical and spirometric evaluation [13], determination of weight and height for the calculation of the body mass index (BMI), assessment with the modified Medical Research Council (MMRC) scale [14] and the 6MWT, based on the recommendations of the American Thoracic Society [15]. The BODE index was determined at this time using the variables identified in this baseline evaluation, as previously described [16]. The BODE index is a multidimensional 10-point scale based on four variables: $\mathrm{FEV}_{1}$ (as percent predicted), distance walked in 6 minutes (expressed in meters), MMRC dyspnea scale, and the body-mass index, in which higher scores indicate a higher risk of death (see Table I). Two duly trained health care professionals were responsible for the evaluations, which were performed by the same evaluators for all patients.

The outpatient group performed all the PR activities in the clinic under the supervision of a physiotherapist. The at-home group performed the same PR activities unsupervised at home. The control group 
did not perform any PR activities and was merely accompanied clinically. The PR program lasted 12 weeks, after which the individuals were evaluated a second time. At the end of the study, all participants were encouraged to continue the PR activities at home. Telephone contact was made each month by a blind evaluator, who inquired about the general health status of the individuals, adverse effects and the continuity of the physical activities. Figure 1 displays the flowchart of the study. All patients (in the three groups) were treated with bronchodilators associated to inhaled corticoids when needed, in accordance with the GOLD guidelines [1].

\section{Interventions \\ Educational program}

During the initial evaluations, all patients took part in an educational program in the auditorium at the clinic, where they received information on the development and progression of COPD, its treatment (both pharmacological and non-pharmacological), the correct use of oxygen for oxygendependent patients and the importance of an exercise-based rehabilitation program. All patients received a chart containing the content of the educational program.

\section{Outpatient pulmonary rehabilitation program}

The outpatient group performed a combination of aerobic and strengthening exercises three mornings a week for three months. Each session was made up of active warm-up exercises, strengthening of upper and lower limbs, aerobic exercises and stretching. The warm-up phase consisted of intercalated callisthenic exercises for different muscle groups, based on the tolerance of each patient.

The upper limb exercises were performed with hand weights while seated comfortably and consisted of 10 repetitions of elbow flexion, 10 repetitions of elbow abduction, 10 repetitions of shoulder abduction and 10 repetitions of shoulder flexion. The lower limb exercises were performed with ankle weights while patients were seated comfortably and consisted of 10 repetitions of hip flexion and 10 repetitions of knee extension. These exercises were performed to the maximal range of motion of each patient, with diaphragm and pursed-lips breathing. The initial load was $50 \%$ of the maximal load achieved on the maximal repetition test (1MR) for the upper and lower limbs [4], with an increase of $0.5 \mathrm{Kg}$ every two weeks until reaching the tolerance limit of each patient. The test for the determination of $1 M R$ consisted of a brief five-minute warm up with upper limb exercises (Kabat diagonals and shoulder flexion-extension), followed by a progressive increase in load until reaching the greatest load moved throughout the total joint range [17].

Aerobic exercise consisted of walking on a tread-

FIGURE 1: FLOWCHART OF STUDY DESIGN

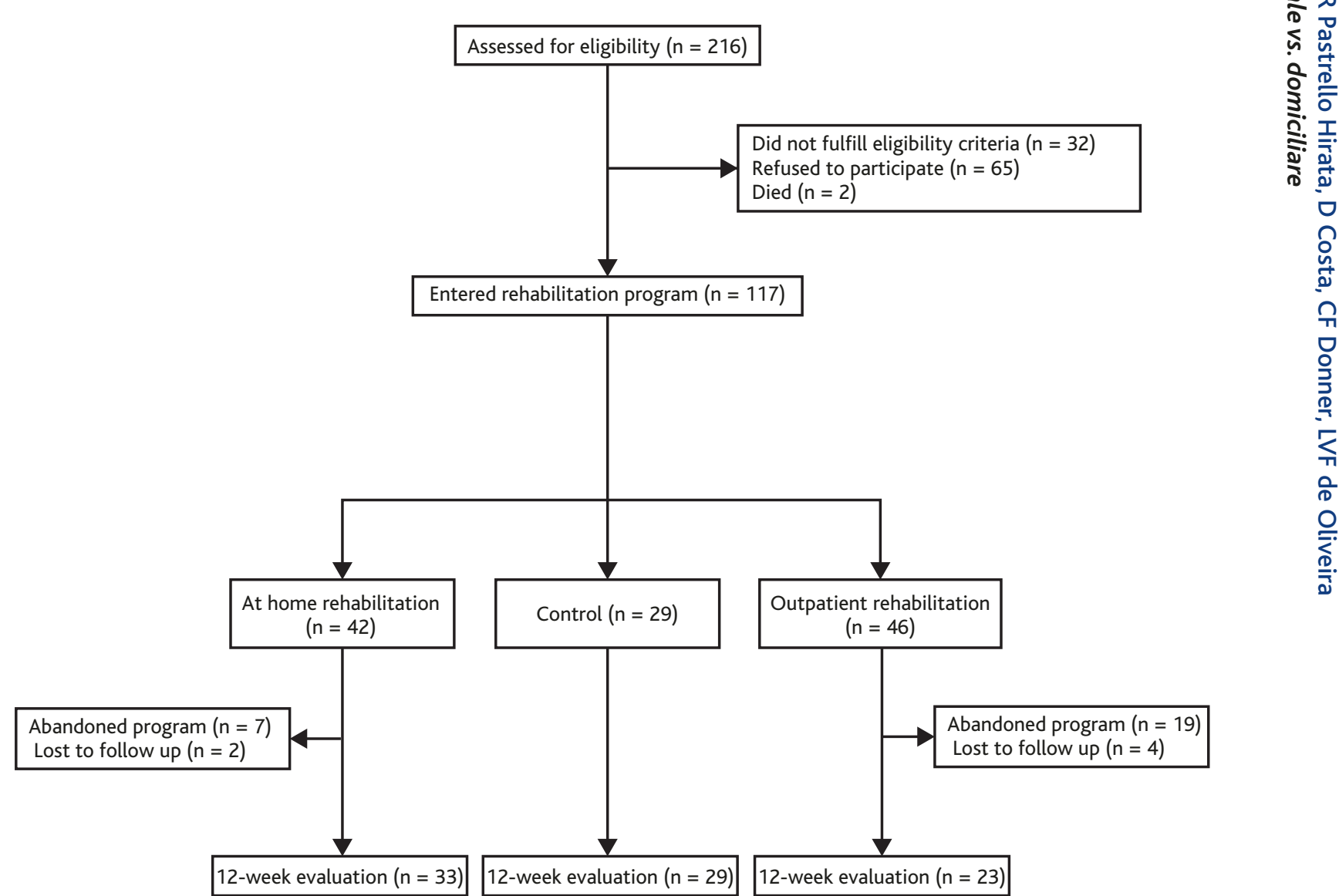


TABLE I: PARAMETERS AND SCORING SYSTEM OF THE BODYMASS, AIRFLOW OBSTRUCTION, DYSPNEA AND EXERCISE CAPACITY (BODE) INDEX*

Variable

Points on BODE Index

\begin{tabular}{lllll}
\hline & 0 & 1 & 2 & 3 \\
\hline FEV $_{1}$ & $\geq 65$ & $50-64$ & $36-49$ & $\leq 35$ \\
$\begin{array}{l}\text { (\% of predicted) } \\
\text { Distance walked }\end{array}$ & $\geq 350$ & $250-349$ & $150-249$ & $\leq 149$ \\
$\begin{array}{l}\text { in } 6 \text { min (m) } \\
\text { MMRC dyspnea }\end{array}$ & $0-1$ & 2 & 3 & 4
\end{tabular}

scale ${ }^{\ddagger}$

Body-mass index ${ }^{\S}>21 \leq 21$

* Cutoff values for the assignment of points are shown for each variable.

Total possible BODE score ranges from 0 to 10

† Forced expiratory volume in 1 second $\left(\mathrm{FEV}_{1}\right)$ categories are based on stages identified by the American Thoracic Society.

* Scores on the modified Medical Research Council (MMRC) dyspnea scale can range from 0 to 4 , with a score of 4 indicating that the patient is too breathless to leave the house or becomes breathless when dressing or undressing.

$\S$ The values for body-mass index were 0 or 1 because of the inflection point in the inverse relation between survival and body-mass index at a value of 21

From [16] mod.

mill for 30 minutes at an intensity of 60 to $80 \%$ of maximal heart rate reached on the $6 \mathrm{MWT}$, which was monitored throughout the training. Patients with oxyhemoglobin desaturation $\left(\mathrm{SpO}_{2} \leq 88 \%\right)$ induced by the initial 6MWT session and those who were already oxygen dependent used oxygen supplementation in order to maintain $\mathrm{SpO}_{2} \geq 92 \%$. In cases of severe dyspnea or complications (dizziness, unusual discomfort in the precordial region or lower limbs), the exercise was immediately interrupted and the patient was evaluated by a pneumologist.

\section{Home pulmonary rehabilitation program}

The at-home group performed the same combination of upper and lower-limb strengthening exercises as the outpatient group for the same amount of time. In cases in which the patient was unable to afford the hand and ankle weights, weights were provided by the clinic for the same function. The patients in this group initially received training from a specialized health care professional at the pneumology clinic and were instructed to follow the proposed protocol at home. Aerobic exercise was performed by means of walks on flat ground at 60 to $80 \%$ of the maximal heart rate reached on the 6MWT performed at the clinic. A heart monitor (Polar S810, Polar ${ }^{\circledR}$, Finland) provided by the clinic to all patients was used to monitor heart rate. A log was designed and the patients were instructed to fill it out at the end of each training session.

During the 12-week period, the individuals received telephone calls from the same professional at the clinic in order to follow up on the load increase, detect problems, clarify questions and reinforce the importance of the rehabilitation. The patients were instructed, in the case of a high degree of dyspnea or any other symptoms of respiratory distress, to reduce the intensity of exercise or cease the exercise and contact the pneumologist. The criteria for at-home oxygen therapy and the protocol for increasing the load on the upper and lower limb exercises were the same as those for the outpatient group.

\section{Statistical analysis}

The sample size was calculated based on the study by Shahin et al. [18], in which the standard deviation on the post-home rehabilitation 6MWT was 19 meters. Considering a clinically significant difference of 54 meters [19], $\alpha=5 \%$ and $90 \%$ power, it was determined that a minimum of 23 patients was needed for each group. The Kolmogorov-Smirnov test was used to test the normality of the distribution of the variables studied. For the intra-group comparisons, Student's paired t-test was used for variables with parametric distribution; the Mann-Whitney test was used for variables with non-parametric distribution. Inter-group comparisons were performed using one-way analysis of variance (ANOVA) and Tukey's post test was used for paired comparisons whenever ANOVA rejected the null hypothesis. The Kruskal-Wallis test was used for inter-group comparisons of variables with non-parametric distribution and the Mann-Whitney test was used for paired comparisons when the null hypothesis was rejected. The chi-square test was used to test associations between groups and intensity of symptoms/hospitalization. All analyses were carried out using the Statistical Package for the Social Sciences, version 13.0 for Windows (SPSS, Chicago, IL, USA), with the level of significance set at $5 \%$.

\section{RESULTS}

Between January 2007 and May 2009, 216 consecutive patients who sought treatment at the Institute of the Lung, Cascavel, PR, Brazil were evaluated and 117 were considered eligible for the study (Figure 1). These patients were divided into three groups: 42 in the at-home group, 46 in the outpatient group and 29 in the control group. After the study had begun, seven patients in the at-home group and 19 in the outpatient group abandoned the study. Moreover, follow up losses occurred with two patients in the at-home group and four in the outpatient group.

\section{Patient characteristics}

Table II shows the demographic and anthropometric data of the study population. Mean age was 69.2 \pm 8.7 years. Mean weight was $67.8 \pm 17.4 \mathrm{Kg}$. Males accounted for $76.5 \%$ of the sample. The main cause related to the development of COPD was past or present smoking habits $(94.1 \%$ of cases); three such cases were likely due to second- 


\begin{tabular}{lccc} 
Characteristics & $\begin{array}{c}\text { At-home } \\
\mathbf{n}=\mathbf{3 3}\end{array}$ & $\begin{array}{c}\text { Outpatient } \\
\mathbf{n}=\mathbf{2 3}\end{array}$ & $\begin{array}{c}\text { Control } \\
\mathbf{n}=29\end{array}$ \\
\hline Age (years) & $66.4 \pm 9.5$ & $71.3 \pm 6.7$ & $70.8 \pm 8.7$ \\
Gender (male/female) & $27 / 6$ & $19 / 4$ & $19 / 10$ \\
Weight $(\mathrm{Kg})$ & $70.0 \pm 18.7$ & $66.1 \pm 13.0$ & $66.7 \pm 19.1$ \\
Height $(\mathrm{cm})$ & $166.9 \pm 9.2$ & $167.0 \pm 8.5$ & $162.9 \pm 10.7$ \\
BMl (kg/m $\left.\mathrm{m}^{2}\right)$ & $25.0 \pm 6.2$ & $23.5 \pm 4.2$ & $24.6 \pm 6.3$ \\
Smoker (ex and current) & $32(97 \%)$ & $20(86.9 \%)$ & $28(96.5 \%)$ \\
Pack years & $61.0 \pm 41.9$ & $24.0 \pm 16.6$ & $32.7 \pm 19.4$
\end{tabular}

Data expressed as mean \pm standard deviation or percentage (in parentheses).

Definition of abbreviation: BMI, body mass index.

hand smoke. Mean tobacco smoke exposure was $43.6 \pm 34.4$ pack years. Another, less frequent cause was exposure to biomass (wood-burning stove and crop burning), which occurred in three patients $(3.5 \%)$. Mean BMI was $24.5 \pm 5.7 \mathrm{~kg} / \mathrm{m}^{2} ; 66$ patients $(77.6 \%)$ had a BMI $>21 \mathrm{~kg} / \mathrm{m}^{2}$.

Table III shows the clinical characteristics of the patient population. Cough was the most common symptom $(90.5 \%)$, followed by dyspnea $(74.1 \%)$, wheezing (71.8\%) and bronchial secretion (36.5\%). Mean post-bronchodilator forced expiratory volume in one second $\left(\mathrm{FEV}_{1}\right)$ in \% of predicted value was $46.5 \pm 22.0 \%$, with the majority of patients in more advanced stages (GOLD III and IV respective- ly $34.1 \%$ and $28.2 \%)$. At the beginning of the study, 40 patients $(47.0 \%$ of the sample) were on longterm home oxygen therapy.

In the intra-group comparisons, the variation in the distance walked on the 6MWT at the end of the 12week period was clinically significant in the outpatient group $(93.6 \pm 70.6$ meters, $p<0.05)$ and athome group $(73.2 \pm 50.2$ meters, $p<0.05)$ in relation to the initial results (Figure 2).

There was no significant difference in the improvement on the 6MWT between the outpatient and athome groups $(p=0.44)$. The control group demonstrated no change on the 6MWT at the end of the study (Figure 3).

TABLE III: CLINICAL CHARACTERISTICS AT BASELINE EVALUATION OF THE THREE STUDY GROUPS

\begin{tabular}{lccc} 
Variables & $\begin{array}{c}\text { At-home } \\
\mathbf{n}=33\end{array}$ & $\begin{array}{c}\text { Outpatient } \\
\mathbf{n}=\mathbf{2 3}\end{array}$ & $\begin{array}{c}\text { Control } \\
\mathbf{n}=29\end{array}$ \\
\hline Dyspnea - MRC 0 & $8(24.2)$ & $6(26.1)$ & $8(27.6)$ \\
Dyspnea - MRC 1 & $9(27.3)$ & $8(34.8)$ & $8(27.6)$ \\
Dyspnea - MRC 2 & $10(30.3)$ & $5(21.7)$ & $10(34.5)$ \\
Dyspnea - MRC 3 & $6(18.2)$ & $4(17.4)$ & $2(6.9)$ \\
Dyspnea - MRC 4 & $0(0)$ & $0(0)$ & $1(3.4)$ \\
Cough & $31(93.9)$ & $20(86.9)$ & $26(89.6)$ \\
Secretion & $12(36.4)$ & $8(34.8)$ & $11(37.9)$ \\
Wheezing & $26(78.8)$ & $15(65.2)$ & $20(69.0)$ \\
Post-bronchodilator spirometry & & & $2.22 \pm 0.55$ \\
FVC (L) & $2.19 \pm 0.71$ & $2.51 \pm 0.82$ & $69.9 \pm 28.0$ \\
FVC (\%) & $68.7 \pm 30.2$ & $79.1 \pm 30.0$ & $0.99 \pm 0.46$ \\
FEV (L) & $1.31 \pm 0.76$ & $1.32 \pm 0.68$ & $41.4 \pm 18.4$ \\
FEV (\%) & $47.5 \pm 23.3$ & $51.5 \pm 23.9$ & $59.2 \pm 20.6$ \\
FEV $/$ FVC (\%) & $69.1 \pm 21.8$ & $65.1 \pm 24.5$ & $2(6.9)$ \\
COPD stage & & & $6(20.7)$ \\
GOLD I & $4(12.1)$ & $2(8.7)$ & $13(44.8)$ \\
GOLD II & $8(24.2)$ & $10(43.5)$ & $8(27.6)$ \\
GOLD III & $11(33.3)$ & $5(21.7)$ & $4(1-9)$ \\
GOLD IV & $10(30.3)$ & $6(26.1)$ & \\
BODE & $4(0-7)$ & $4(0-8)$ &
\end{tabular}

Data expressed as absolute number and percentage (in parentheses) or mean \pm standard deviation.

Definition of abbreviatons: COPD, chronic obstructive pulmonary disease; $\mathrm{FEV}_{1}$, forced expiratory volume in 1 second; FVC, forced vital capacity; GOLD, Global initiative for chronic obstructive lung disease; MRC, Medical Research Council. 
FIGURE 2: INTRA-GROUP RESULTS OF DISTANCE WALKED ON SIX-MINUTE WALK TEST BEFORE AND AFTER REHABILITATION PROGRAM

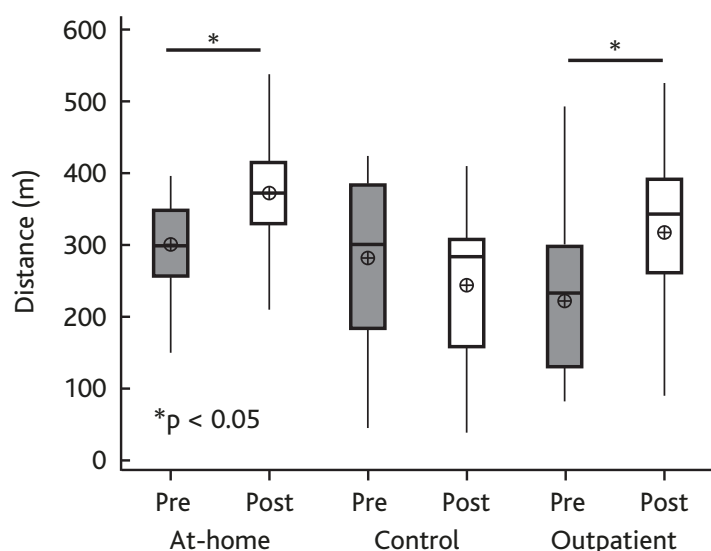

There was a significant reduction in the BODE index in the outpatient and at-home groups at the end of the 12 -week period $(p<0.001)$ and the patients in the control group also demonstrated a significant improvement $(p=0.01)$ (Figure 4$)$. In the inter-group comparisons, there was no significant difference in the variation in BODE index between the outpatient and at-home groups ( $p=0.90)$, whereas both these groups achieved a significantly greater reduction in the index in comparison to the control group $(p=0.010$ and $p=0.016$, respectively).

\section{DISCUSSION}

PR focuses on the multiple needs of patients with COPD and is one of the approaches to reducing disability stemming from this progressive, chronic disease $[4,20]$. However, there is limited availability of PR programs in most countries and few patients are submitted to this treatment modality [7-9].

FIGURE 3: VARIATION ON SIX-MINUTE WALK TEST BETWEEN GROUPS BEFORE AND AFTER REHABILITATION PROGRAM

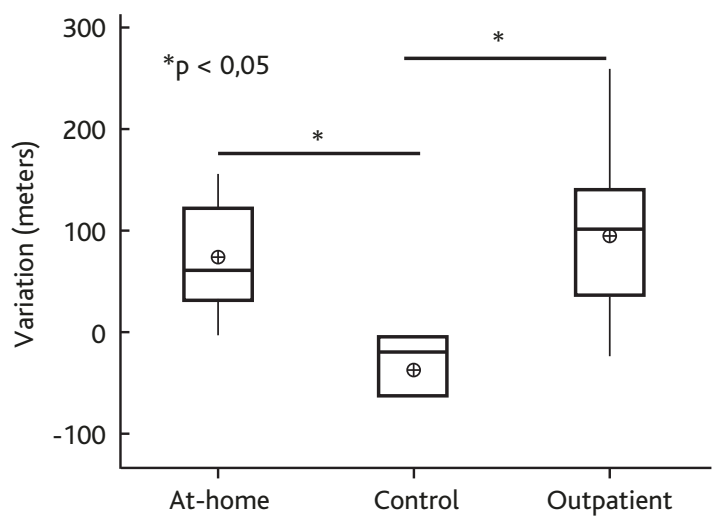

FIGURE 4: BODE INDEX VARIATION BEFORE AND AFTER REHABILITATION PROGRAM

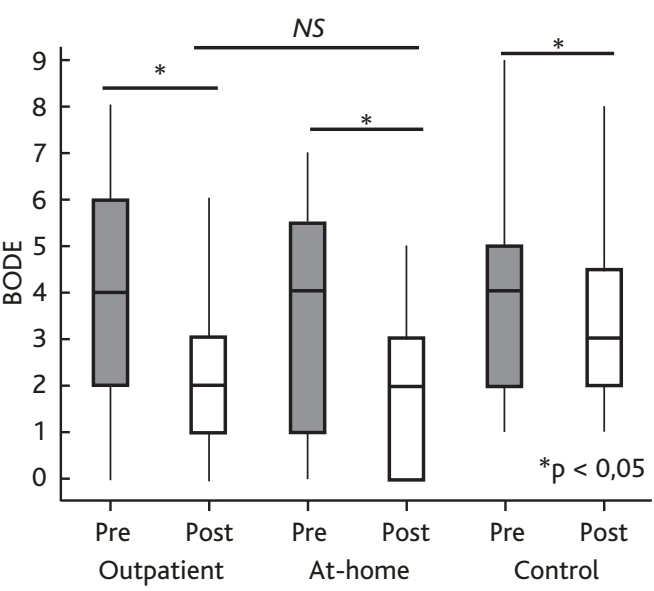

Moreover, PR carried out in a clinical setting and based on hospital guidelines requires qualified health care professionals, equipment and facilities, which are expensive to maintain and this cost contributes toward the reduction in the availability of PR at health care services [5-7].

The 6MWT is a widely accepted method for determining functional capacity for exercise, being commonly used in field studies due to its low-cost, reproducibility, objectivity and easy application in relation to patient age and education level $[15,21]$. It has also proven to be a predictor of post-pulmonary rehabilitation survival $[16,22]$. According to Weisman et al., the 6MWT has proven more sensitive in detecting decline in $\mathrm{SpO}_{2}$ than a maximal increment test on cycle ergometer for patients with COPD [23].

In the present study, the variation in the distance walked on the 6MWT following participation in the PR program was statistically significant in both the outpatient and at-home groups in comparison to the control group $(p<0.05)$. The mean variation was $93.61 \pm 70.57$ meters in the outpatient group and $73.21 \pm 50.21$ meters in the at-home group. According to Redelmeier et al., an increase in the distance walked on the 6MWT of at least 54 meters over baseline values is clinically important in terms of the improvement in physical capacity [19]. This has been confirmed in a number of studies assessing PR programs $[24,25]$.

The BODE index is considered a better predictor of the risk of mortality due to both respiratory and non-respiratory causes when compared to $\mathrm{FEV}_{1}$ alone [16]. In the present study, all groups demonstrated a reduction in the BODE index. However, the reduction was significantly greater in the outpatient and at-home groups. The fact that an improvement in the BODE index was found in all groups, including the control group, is probably due to the fact that all patients, regardless of the rehabilitation modality, were rigorously treated with bronchodilators and inhaled corticosteroids, with an optimiza- 
tion of their pharmacological management during the course of the study.

For all the variables analyzed, the clinical benefits achieved with PR performed in the clinical setting were not significantly greater than those achieved in the self-monitored home modality. This demonstrates the efficacy of the home modality for the management of patients with COPD, which allows clinical benefits, lower costs and possibly greater adherence due to the non-necessity of transportation to specialized clinics. Two previous studies have assessed the effectiveness of self-monitored home PR programs, but neither of them used a control group $[27,28]$. In a multicenter randomized clinical trial, Maltais et al. found that both outpatient and at-home PR interventions were equally effective in promoting a clinical improvement in dyspnea [26].

Another positive aspect of our study is that the dropout rate was notably less in the at-home group than in the outpatient group (7 vs. 19). This difference is likely due to the fact that carrying out a rehabilitation program at home is logistically easier for patients than travelling to a hospital clinic 3 times a week.

The present study had some limitations. The study was carried out at a single center, more specifically in a specialist pulmonology clinic, and subjects in the different groups were not matched for age, BMI, smoking status, $\mathrm{FEV}_{1}$, or baseline 6MWD. Moreover, there was no evaluation of health-related quality of life, which is another clinically important outcome.

\section{References}

1. Global Initiative for Chronic Obstructive Lung Disease. Global strategy for the diagnosis, management and prevention of chronic obstructive pulmonary disease. Bethesda: NHLBI/WHO workshop report; 2009 [accessed 04/19/2009]. www.goldcopd.com

2. O'Donnell DE, Hernandez $P$, Aaron S, Bourbeau J, Marciniuk D, Hodder R, Balter M, Ford G, Gervais A, Goldstein R, Maltais F, Road J, McKay V, Schenkel J; Société candienne de thoracologie. Canadian Thoracic Society COPD guidelines: summary of highlights for family doctors. Can Respir J 2003;10:463-466.

3. Lacasse Y, Goldstein R, Lasserson TJ, Martin S. Pulmonary rehabilitation for chronic obstructive pulmonary disease. Cochrane Database Syst Rev 2006;4:CD003793.

4. Nici L, Donner C, Wouters E, Zuwallack R, Ambrosino N, Bourbeau J, Carone M, Celli B, Engelen M, Fahy B, Garvey C, Goldstein R, Gosselink R, Lareau S, Macintyre N, Maltais F, Morgan M, O'Donnell D, Prefault C, Reardon J, Rochester C, Schols A, Singh S, Troosters T; ATS/ERS Pulmonary Rehabilitation Writing Committee. American Thoracic Society/European Respiratory Society statement on pulmonary rehabilitation. Am J Respir Crit Care Med 2006;173:1390-1413.

5. Brooks D, Sottana R, Bell B, Hanna M, Laframboise L, Selvanayagarajah S, Goldstein R. Characterization of pulmonary rehabilitation programs in Canada in 2005. Can Respir J 2007;14:87-92.

\section{CONCLUSION}

The present study, despite the above limitations, demonstrates that a self-monitored home pulmonary rehabilitation program can achieve similar results to a supervised outpatient pulmonary rehabilitation program and is a valid alternative in the therapeutic approach to patients with COPD. The data we provide show that self-monitored exercise, truly home-based, following a short period of instruction and education, can achieve equivalent benefits in exercise capacity and body-index scores. Considering the limited access to pulmonary rehabilitation programs worldwide, offering patients the opportunity of a home-based rehabilitation program can overcome the problems related to outpatient rehabilitation (i.e. it is costly to provide and many patients have problems travelling to the center several times per week). Hence, a broadscale use of the home program is recommended, as this treatment modality is not limited by geographic location and would enable a greater access of patients with COPD to pulmonary rehabilitation.

ACKNOWLEDGMENTS This study received support from the Brazilian fostering agencies Fundação de Amparo a Pesquisa do Estado de São Paulo and Conselho Nacional de Desenvolvimento Científico e Tecnológico. The authors Dirceu Costa and Luis V. Franco de Oliveira are respectively PQI and PQII research productivity grant awardees from the Conselho Nacional de Desenvolvimento Científico e Tecnológico, Brazil.

CONFLICT OF INTEREST STATEMENT: None of the authors has any conflict of interest to declare in relation to the subject matter of this manuscript.

6. Bickford LS, Hodgkin JE, Mclnturff SL. National pulmonary rehabilitation survey. Update. J Cardiopulm Rehabil 1995;15:406-411.

7. Yohannes AM, Connolly MJ. Pulmonary rehabilitation programmes in the UK: a national representative survey. Clin Rehabil 2004;18:444-449.

8. Maltais F, Bourbeau J, Lacasse $Y$, Shapiro S, Perrault $H$, Penrod JR, Baltzan M, Rouleau M, Julien M, Paradis B, Audet R, Hernandez P, Levy RD, Camp P, Lecours R, Picard D, Bernard S. A Canadian, multicentre, randomized clinical trial of home-based pulmonary rehabilitation in chronic obstructive pulmonary disease: rationale and methods. Can Respir J 2005;12:193-198.

9. Strijbos JH, Postma DS, van Altena R, Gimeno F, Koëter GH. A comparison between an outpatient hospital-based pulmonary rehabilitation program and a home-care pulmonary rehabilitation program in patients with COPD. A follow up of 18 months. Chest 1996;109:366-372.

10. Wijkstra PJ, van der Mark TW, Kraan J, van Altena R, Koëter $\mathrm{GH}$, Postma DS. Effects of home rehabilitation on physical performance in patients with chronic obstructive pulmonary disease (COPD). Eur Respir J 1996;9:104-110.

11. Cambach W, Chadwick-Straver RV, Wagenaar RC, van Keimpema AR, Kemper HC. The effects of a communitybased pulmonary rehabilitation programme on exercise tolerance and quality of life: a randomized controlled trial. Eur Respir J 1997;10:104-113. 
12. Miravitlles M, Murio C, Tirado-Conde G, Levy G, Muellerova H, Soriano JB, Ramirez-Venegas A, Ko FW, Canelos-Estrella B, Giugno E, Bergna M, Chérrez I, Anzueto A. Geographic differences in clinical characteristics and management of COPD: the EPOCA study. Int J Chron Obstruct Pulmon Dis 2008;3:803-814.

13. Miller MR, Hankinson J, Brusasco V, Burgos F, Casaburi R, Coates A, Crapo R, Enright $\mathrm{P}$, van der Grinten $\mathrm{CP}$, Gustafsson $P$, Jensen R, Johnson DC, Maclntyre N, McKay R, Navajas D, Pedersen OF, Pellegrino R, Viegi G, Wanger J; ATS/ERS Task Force. Standardisation of spirometry. Eur Respir J 2005;26:319-338.

14. Bestall JC, Paul EA, Garrod R, Garnham R, Jones PW, Wedzicha JA. Usefulness of the Medical Research Council (MRC) dyspnoea scale as a measure of disability in patients with chronic obstructive pulmonary disease. Thorax 1999;54:581-586.

15. ATS Committee on Proficiency Standards for Clinical Pulmonary Function Laboratories. ATS statement: guidelines for the six-minute walk test. Am J Respir Crit Care Med 2002;166:111-117.

16. Celli BR, Cote CG, Marin JM, Casanova C, Montes de Oca M, Mendez RA, Pinto Plata V, Cabral HJ. The body-mass index, airflow obstruction, dyspnea, and exercise capacity index in chronic obstructive pulmonary disease. $\mathrm{N}$ Engl J Med 2004;350:1005-1012.

17. Powers SK, Howley ET. Fisiologia do Exercício: Teoria e Aplicação ao Condicionamento e ao Desempenho. São Paulo: Manole, 2000.

18. Barakat S, Michele G, George P, Nicole V, Guy A. Outpatient pulmonary rehabilitation in patients with chronic obstructive pulmonary disease. Int J Chron Obstruct Pulmon Dis 2008;3:155-162.

19. Redelmeier DA, Bayoumi AM, Goldstein RS, Guyatt GH. Interpreting small differences in functional status: the Six Minute Walk test in chronic lung disease patients. Am J Respir Crit Care Med 1997;155:1278-1282.

20. Lacasse Y, Martin S, Lasserson T], Goldstein RS. Meta-analy- sis of pulmonary rehabilitation for chronic obstructive pulmonary disease. A Cochrane systematic review. Eura Medicophys 2007;43:475-485.

21. Casanova C, Cote CG, Marin JM, de Torres JP, Aguirre-Jaime A, Mendez R, Dordelly L, Celli BR. The 6-min walking distance: long-term follow up in patients with COPD. Eur Respir J 2007;29:535-540.

22. Gerardi DA, Lovett L, Benoit-Connors ML, Reardon JZ, ZuWallack RL. Variables related to increased mortality following out-patient pulmonary rehabilitation. Eur Respir J 1996;9:431-435.

23. Weisman IM, Zeballos RJ. Clinical exercise testing. Clin Chest Med 2001;22:679-701.

24. Troosters T, Casaburi R, Gosselink R, Decramer M. Pulmonary rehabilitation in chronic obstructive pulmonary disease. Am J Respir Crit Care Med 2005;172:19-38.

25. Riario-Sforza GG, Incorvaia C, Paterniti F, Pessina L, Caligiuri R, Pravettoni C, Di Marco F, Centanni S. Effects of pulmonary rehabilitation on exercise capacity in patients with COPD: a number needed to treat study. Int J Chron Obstruct Pulmon Dis 2009;4:315-319.

26. Maltais F, Bourbeau J, Shapiro S, Lacasse $Y$, Perrault H, Baltzan M, Hernandez P, Rouleau M, Julien M, Parenteau S, Paradis B, Levy RD, Camp P, Lecours R, Audet R, Hutton B, Penrod JR, Picard D, Bernard S; Chronic Obstructive Pulmonary Disease Axis of Respiratory Health Network, Fonds de recherche en santé du Québec. Effects of homebased pulmonary rehabilitation in patients with chronic obstructive pulmonary disease: a randomized trial. Ann Intern Med 2008;149:869-878.

27. Lomundal BK, Steinsbekk A. Observational studies of a one year self-management program and a two year pulmonary rehabilitation program in patients with COPD. Int J Chron Obstruct Pulmon Dis 2007;2:617-624.

28. Griffiths TL, Phillips CJ, Davies S, Burr ML, Campbell IA Cost effectiveness of an outpatient multidisciplinary pulmonary rehabilitation programme. Thorax 2001;56:779784 